\title{
RECEPCIÓN DE DOCUMENTOS
}

1. La recepción de los artículos se hará en el Departamento de Transferencia e Información Tecnológica, teléfono 2231 3991, dirección electrónica comiteeditorial@inta.go.cr

2. La recepción o no de los escritos será competencia del Comité Editorial del INTA, el cual hará una valoración inicial de acuerdo a las normas y procedimientos para la publicación de documentos en la revista Alcances Tecnológicos del INTA.

3. Si el documento presentado es del INTA, el autor principal debe presentar una nota del programa correspondiente en la que se avala su publicación y se indica que no ha sido sometido a publicación en otra revista.

4. Si el documento presentado no es del INTA, el autor principal debe presentar una nota de la institución para la cual labora, en la que se autoriza su publicación y se indica que no ha sido sometido a publicación en otra revista.
5. Si en el documento presentado figuran varios autores, cada uno de ellos debe autorizar por escrito la publicación del documento. Además, deben indicar la aprobación del orden de los autores e indicar autor responsable para correspondencia.

6. Para aceptar o no la publicación el Comité Editorial somete los artículos a revisión. Para esto dispone de una lista de revisores internos y externos.

7. Los artículos son revisados por tres especialistas dos del INTA (revisores internos) y otro de otra institución (revisor externo).

8. Los revisores deben indicar las observaciones en el documento y completar el cuadro de calificación. Pueden utilizar la versión electrónica de control de cambios.

9. Si los autores no aceptan las sugerencias de los especialistas, deben enviar una nota al Comité Editorial explicando las razones; si es necesario el Comité Editorial elegirá otro especialista, el cual fungirá como árbitro.

\section{REVISIÓN Y ACEPTACIÓN DE DOCUMENTOS}

1. Los revisores internos tendrán un plazo máximo de un mes para entregar las publicaciones revisadas. A los revisores externos se les sugerirá el mismo tiempo para revisarlo.

2. Cuando el artículo es devuelto por los revisores, el/la editor/a dispondrá de ocho días hábiles para enviarlo a los autores con una nota en la que se indican las correcciones respectivas. Por su parte, los autores contarán con un plazo máximo de 15 días hábiles para hacer las correcciones y devolverlo, a el/la editor/a.
3. Una vez que el artículo es revisado y corregido, lo cual es corroborado por el Comité Editorial, se autoriza su publicación.

4. Luego de aprobada la publicación del artículo por el Comité Editorial, los autores deben revisar exhaustivamente todo el texto, para consentir su publicación. 


\section{REDACCIÓN DE LOS DOCUMENTOS}

1. En la redacción de los artículos se deben utilizar las normas de la Real Academia Española y las unidades de medida del Sistema Métrico Decimal.

- Las unidades no llevan punto, se escriben con minúscula y no tienen plural. Algunos ejemplos son: kilogramo $(\mathrm{kg})$, gramo $(\mathrm{g})$, metro $(\mathrm{m})$, hectárea $(\mathrm{ha})$, milímetro $(\mathrm{mm})$, miligramo (mg) litro (I), metros sobre el nivel del mar (msnm).

- Los elementos (N, P entre otros) y los compuestos químicos (como, por ejemplo: $\mathrm{NaOH}, \mathrm{NaCl}$ ) se escriben con mayúscula.

- Cuando las unidades no están precedidas por un número, se expresan por su nombre completo sin utilizar su abreviatura. Por ejemplo: metro en lugar de $\mathrm{m}$.

- Los decimales se indican con coma; los miles y los millones con un espacio. Ejemplo: 8327 451,25. Los números de cuatro cifras se escriben sin espacios. Ejemplo: 2458.
- En el caso de los números del cero al nueve, cuando no van seguidos de unidades, se escriben con palabra; y números para valores iguales o mayores a 10.

2. Cuando en los artículos se citan productos de origen químico o biológico, se deben utilizar solamente los nombres genéricos. Ejemplos: Terbufos, Oxidemeton Metil. No se acepta el uso de nombres comerciales. Además, los productos mencionados deben estar registrados y aprobados (para el cultivo) en la base de datos del Registro de Insumos y Fiscalización del Servicio Fitosanitario del Estado. Disponible en https://www.sfe.go.cr/

3. Los cuadros y figuras que no son propiedad del autor, deben poseer fuente.

\section{FORMATO PARA CADA SECCIÓN DE LOS DOCUMENTOS}

\section{Título}

Tiene que ser breve, específico, resumido, en mayúscula y en negrita. No más de 14 palabras. Él o los autores deben indicar los nombres científicos en cursiva, cuando consideren que el nombre común no es muy conocido (Agronomía Mesoamericana 2017).
Lo que no se recomienda en los títulos (Araya 2012) ${ }^{1}$.

- Estudio sobre.......

- Informe de..........

- Investigación acerca de.......

- Contribución a...............

- Resultados de un estudio sobre.......

- Análisis de los resultados......... 
Los nombres científicos (género, especie, cultivar y el nombre del clasificador) deberán ser citados para cada organismo en su primera mención, posteriormente se puede continuar usando el nombre común.

\section{Título resumido}

No debe ser mayor a ocho palabras (Agronomía Mesoamericana 2017).

\section{Autor(es)}

Se consideran autores los individuos o entidades responsables de los contenidos intelectuales de las publicaciones. El orden en el que se mencionan va de acuerdo con su contribución y aportes en la investigación y se colocan debajo del título. Con una nota al pie de página indicando la institución para la cual labora(n), la dirección postal y electrónica. Se omiten los grados académicos. El número total de autores no debe ser superior a seis.

\section{Resumen}

Se coloca después del nombre de los autores y presenta en forma concisa el mensaje del artículo, describiendo brevemente los materiales y condiciones más relevantes del experimento. Debe indicar el año y lugar, los resultados obtenidos y las conclusiones más importantes. Las oraciones usadas deben ser racionales, objetivas y justificar el porqué de la investigación y el objetivo, evitando describir directamente los materiales y métodos. La extensión no debe exceder las 250 palabras a espacio seguido y en un solo párrafo.

\section{Palabras clave}

Debajo del resumen se deben incluir de cinco a siete palabras o frases clave, no deben formar parte del título.

\section{Introducción}

Define el problema que motiva la investigación y al final de esta sección se indican los objetivos o razones del estudio. Pueden incluirse citas bibliográficas para ayudar a la definición del problema y del trabajo. La extensión de esta debe ser de aproximadamente 350 palabras (MAG 1990).

\section{Materiales y métodos}

En esta sección se recomienda describir en forma bien detallada la ubicación, la fecha de inicio y término, el ambiente, los materiales (si se usa equipo de medición, incluir marca y modelo), las técnicas, los tratamientos, el diseño experimental, los análisis estadísticos y las variables a evaluar expuestas con suficiente claridad para que otros científicos puedan repetir el estudio. Si el método es muy conocido, solamente se incluyen referencias bibliográficas aclaratorias; si es nuevo o modificado se debe escribir nuevamente. Escribir en orden cronológico (MAG 1990).

\section{Resultados y discusión}

Ambas partes deben ir juntas. Los resultados describen la información generada por la investigación; debe escribirse en forma concisa y siguiendo una secuencia lógica, usando cuadros y figuras, a los cuadros se les debe indicar su enunciado en la parte superior y a las figuras en la parte inferior, en ambos casos, si no son propiedad del autor se les debe anotar la fuente. Las fotografías, se anotan como figuras y su numeración se debe ajustar a la misma secuencia. Los cuadros se presentan sin divisiones internas. Los cuadros y figuras deben estar ubicados inmediatamente después de donde se mencionan, deben ser auto explicativos y la información debe presentarse en forma completa, clara y concisa, de tal forma que no se tenga que recurrir al texto para entender el resultado presentado. Los decimales se deben usar de acuerdo al grado de precisión que se tomaron los datos, si no, se debe redondear apropiadamente. Además de la descripción del contenido de la figura, en el título debe contener el lugar y el año en que se hizo el trabajo de investigación. 
En la discusión la estadística se debe usar para explicar las diferencias de los tratamientos, debe usarse como una herramienta para probar la(s) hipótesis propuesta(s), con una base objetiva. Suministrar la significancia de las pruebas.

Se discutirán los resultados obtenidos, comparándolos con otros trabajos afines para dar interpretaciones o hacer deducciones lógicas sobre las diferencias o concordancias encontradas.

En la discusión se debe explicar hasta qué punto los resultados obtenidos contribuyen a la solución del problema (limitantes) y qué puede traducirse en recomendaciones, aplicaciones, sugerencias e hipótesis (MAG 1990).

\section{Conclusiones o consideraciones finales}

Van incluidas en la discusión.

\section{Literatura citada}

La lista de la literatura citada, para todos los tipos de documentos aceptados, debe estar conformada por no menos de diez citas bibliográficas recientes $(90 \%$ de los últimos 10 años), las citas deben reforzar científicamente lo expresado en el documento, además deben ser de fácil acceso para consultar en centros de documentación, bibliotecas o internet. Se deben utilizar las Normas de Redacción (IICA-CATIE) en su 5 edición (IICA y CATIE 2016). Disponible en http://repiica.iica.int/docs/B4013e/B4013e.pdf

\section{LITERATURA CITADA}

Agronomía Mesoamericana, Costa Rica. 2017. Instructivo para los autores/Instructions for authors. (en línea). San José, Costa Rica. 7 p. Consultado 28 abr. 2017. Disponible en http:// revistas.ucr.ac.cr/index.php/agromeso/about/ submissions\#authorGuidelines

IICA (Instituto Interamericano de Cooperación para la Agricultura, Costa Rica); CATIE (Centro Agronómico Tropical de Investigación y Enseñanza, Costa Rica). 2016. Redacción de referencias bibliográficas. 5 ed. San José, Costa Rica. Bibliotecas IICA-CATIE. 79 p.

MAG (Ministerio de Agricultura y Ganadería). 1990. Normas para la publicación de artículos científicos en la revista investigación agrícola. Investigación Agrícola 4(2):3-6. 
